\title{
Priming with a combination of proangiogenic growth factors improves wound healing in normoglycemic mice
}

\author{
MAXIMILIAN ACKERMANN ${ }^{1}$, TANJA WOLLOSCHECK $^{1}$, AXEL WELLMANN $^{2}$, \\ VINCENT W. $\mathrm{LI}^{3,4}$, WILLIAM W. $\mathrm{LI}^{4}$ and MORITZ A. KONERDING ${ }^{1}$
}

\begin{abstract}
${ }^{1}$ Institute of Functional and Clinical Anatomy, University Medical Center of the Johannes Gutenberg University Mainz, Mainz; ${ }^{2}$ Institute of Pathology Celle, Wittinger Strasse 14, Celle, Germany; ${ }^{3}$ Angiogenesis and Wound Center, Brigham and Women's Hospital, Harvard Medical School, Boston, MA; ${ }^{4}$ The Angiogenesis Foundation, Cambridge, MA, USA
\end{abstract}

Received October 25, 2010; Accepted December 20, 2010

DOI: 10.3892/ijmm.2011.641

\begin{abstract}
Growth factors and/or angiogenic factors are supposed to improve wound healing. The aim of our study was to evaluate the effects of subcutaneous pretreatment with combinatory proangiogenic factors on wound closure, mechanical properties, vessel density and morphology. Twenty-eight $\mathrm{Balb} / \mathrm{c}$ mice were divided equally into two groups. A mixture of VEGF $(35.0 \mu \mathrm{g})$, bFGF $(2.5 \mu \mathrm{g})$ and PDGF $(3.5 \mu \mathrm{g})$ was administered subcutaneously 3,5 and 7 days to 14 mice before full thickness skin punch biopsy wounding, whereas 14 control animals received three injections of $0.2 \mathrm{ml}$ saline solution. Wound sizes were assessed daily and the repaired tissues were harvested 7 days after complete wound closure. Complete closure ( $\geq 95 \%$ healing of initial wound area) was reached in all proangiogenic pretreated animals on day 10 , whereas controls needed 13 days for complete closure. Tensile strengths were nearly twofold higher compared to the controls $(\mathrm{p} \leq 0.01)$. The punch biopsy material revealed 4.2 -fold higher vessel densities in the proangiogenic pretreated group. On day 17 , the vessel densities in the proangiogenic pretreated wounds were also 3.2-fold higher compared to the untreated controls. No significant differences were seen in the collagen ratio. Pretreatment with proangiogenic factors revealed several significant effects on wound healing: faster time to closure, a higher vessel density and a better functional outcome. These results suggest a beneficial effect of pretreatment with combinatory growth factors in mouse skin wounds without impaired wound healing. This might be exploited in further investigations in diabetic healing as a therapeutic approach for elective surgery.
\end{abstract}

Correspondence to: Dr Moritz A. Konerding, Institute of Functional and Clinical Anatomy, University Medical Center Johannes Gutenberg University Mainz, D-55099 Mainz, Germany E-mail: konerdin@uni-mainz.de

Key words: priming, proangiogenic, healing, tensile strength, thermography

\section{Introduction}

Angiogenesis represents a fundamental control point in many pathological and physiological processes (1). The identification of numerous signal transduction pathways as well as the availability of different purified growth factors has enabled therapeutic approaches in various disease areas (2). Similarities in the morphology between wounds and tumors as 'wounds that do not heal' (3) has raised interest in manipulating wound healing by the application of growth factors (4). Furthermore, different processes of tumor vasculature have to be targeted for gaining unbiased results (5).

Impaired microcirculation, which may lead to impaired wound healing, represents a central pathological comorbidity (6) of many diseases such as diabetes (7) or peripheral arterial disease (PAD) that tends to result in scarring and delayed and compromised mechanical skin healing (8). Wound healing is strongly dependent on the formation of granulation tissue, which in turn is intimately correlated with the induction of new vessel formation (9). Angiogenesis represents a complex process that relies on the extracellular matrix (ECM) of the wound bed as well as on the migration and mitogenic stimulation of endothelial cells (10). Therefore, several investigations have examined whether stimulation of angiogenesis could promote wound healing.

The effects of many proangiogenic growth factors in wound healing have been investigated (11). Besides VEGF that facilitates tissue repair by proliferating pre-existing endothelial cells and increasing vascular permeability (2), FGF and PDGF regulate predominantly the synthesis and deposition of ECM components (12), but they also intensify wound angiogenesis. PDGF stimulates macrophages and secretes other growth factors of importance in the healing process and several matrix molecules, like fibronectin, collagen and proteoglycans (13).

The therapeutic experiences with these proangiogenic growth factors have been ambivalent: mode and time of application (14) are thought to have great influence on wound healing. In addition, the application of one individual factor (15) may not do justice to the complex mechanisms involved in tissue repair $(16,17)$. Not only the way of application, but also the time may have an impact on the process of growth stimulation (18). Cross-talk and a complex redundancy of 
growth factors appear to be inherent in the tissue repair system (19).

Clinical studies have shown that growth factor stimulation facilitates healing in diabetic patients (20). Other studies of other growth factors have been inconclusive. Recent observations in mouse wound healing models suggest that the topical application of single growth factors does not result in faster wound healing (21). The combination of different key players acting on vessel formation, stabilization and the interaction with the extracellular matrix and the surrounding tissues seems to be a much more powerful approach.

\section{Methods}

Animals. Twenty-eight female Balb/c mice, 25-33 g, were used in all experiments. They were obtained from the Central Animal Facilities of the University of Mainz and housed in an approved animal care facility with $12 \mathrm{~h}$ light cycles. Food and water were provided ad libitum. The care of the animals was consistent with the legal guidelines and all experiments were conducted after approval by the local animal welfare authorities (Licence no: 1.5 177-07/041-2). Animals were kept in individual cages during the experiment in order to avoid biting and interference with the wounds. While the wounds were still open and wet, only soft tissue paper was used instead of conventional bedding in order to avoid wound irritation or contamination.

Growth factor priming. The dorsal skin of the mice was shaved and depilated. Three, 5, and 7 days prior to surgery, a combination of $35.0 \mu \mathrm{g}$ VEGF, $2.5 \mu \mathrm{g}$ bFGF and $3.5 \mu \mathrm{g}$ PDGF (R\&D Systems, Minneapolis, $\mathrm{MN}$ ) dissolved in $0.2 \mathrm{ml}$ saline solution was injected subcutaneuously $1.0 \mathrm{~cm}$ paramedian in normoglycemic mice. The control group animals received $0.2 \mathrm{ml}$ saline solution (B. Braun, Melsungen, Germany). This combination of different growth factors and the respective dosage based on own preliminerary tests and on data from the existing literature $(16,17,20)$.

Surgery. Mice were anesthetized with an intraperitoneal injection of avertin (1.5 ml/100 g bodyweight, 2,2,2-tribromoethanol; Sigma-Aldrich, Munich, Germany). Immediately before biopsy an area of $15 \times 15 \mathrm{~mm}$ was shaved again using disposable shavers followed by skin disinfections with $70 \%$ ethanol. Under sterile conditions 8-mm circular full thickness punch biopsy wounds were made using disposable punches (Stiefel, Offenbach, Germany) in the midline of the lumbar dorsal skin of the mice.

Wound size analysis. Digital photographs (JVC KY-F75U, JVC, Yokohama, Japan) were taken at the time of surgery and thereafter daily from a distance of $18 \mathrm{~cm}$. A ruler (length: $10 \mathrm{~mm}$ ) was placed on the back of the animal for a reference. The wound areas were measured by tracing wound margins with a fine resolution computer stylus and were analyzed by means of a morphometry software (Diskus 4.80, Hilgers, Königswinter; Germany). The percentages of the wound areas were calculated as actual residuals in reference to the wound areas of day 1 after surgery. Wound closure was defined as $\geq 95 \%$ wound closure according to the FDA-guidance for industry 'Chronic ulcers and burn wounds - Developing products for treatment' (22).

Infrared thermography. To assess the possible effects of angiogenic factors on local perfusion, an infrared thermographic system (Varioscan 3021-ST, Jenoptik AG, Jena, Germany) was used. Thermograms were taken from non-anesthetized mice every three days post-surgery at a distance of $12 \mathrm{~cm}$ from the camera. The computerized evaluation was carried out using the Irbis ${ }^{\circledR}$ control software (version 2.2, InfraTec $\mathrm{GmbH}$, Dresden, Germany). Temperatures were measured in the wound bed (23), the wound margin and the adjacent unwounded tissue with line and area scans. The wound itself was easily identified because of the relative local hyperthermia and was confirmed by comparing the IRT-image with the macroscopic appearances. A two millimetres wide area encircling the wound bed was defined as the wound margin. Unwounded skin at least $4 \mathrm{~mm}$ distant from the wound margin was used for reference measurements.

Tissue sampling and histology. The animals were sacrificed on day 17 after surgery. The central parts of the wound area were used for maximum tensile strength measurements, and the adjacent parts for histology and immunochemistry. Sections $(5 \mu \mathrm{m})$ of paraffin-embedded specimens were stained with hematoxylin-eosin and picrosirius red according to standard protocols. H\&E-stained sections were used to assess the scar dimensions at the upper, the middle and the lower dermis, the scar thickness, the granulation tissue quality and the progress of remodeling. Thicknesses of the individual skin layers were measured with the image analyzing software Diskus 4.80. All sections underwent blind quantifaction by an independent observer.

Picrosirius red staining was used to quantify the collagen content (24), which was expressed as percentage of red-stained pixels using the image analyzing software KS300 (Kontron AG, Eching, Germany). Areas of green (type III collagen-like) and red (type I collagen-like) were calculated for each field captured. The same settings were used for all analyses.

Immunohistochemical staining of endothelial cells was performed using a monoclonal antibody against CD31 (BD Biosciences Pharmingen, Heidelberg, Germany). Antibody binding was visualized via a three-step staining procedure using a biotinylated polyclonal anti-rat IgG secondary antibody (DakoCytomation GmbH, Hamburg, Germany) and the streptavidin horseradish peroxidase reaction together with the DAB detection system. Vessel densities were assessed using a Weibel grid (25) and expressed as percent vessel surface area.

Tensile strength measurements. Test strips were punched out from the harvested wound vertically to the craniocaudal axis. The test strips had a defined hourglass form with $3 \mathrm{~mm}$ width at the narrowest part constituting a predetermined breaking point. The design of the hourglass form was based on material testing standards. Test strips without the hourglass form would inevitably tear at the wedge grips, where the tissue was already bruised. The breaking strength test device consisted of two opposing gripping jaws which fixed the tissue strip. The electric motor driven gripping jaws were moved apart with a constant strain rate of $0.5 \mathrm{~mm} / \mathrm{s}$ under displacement 

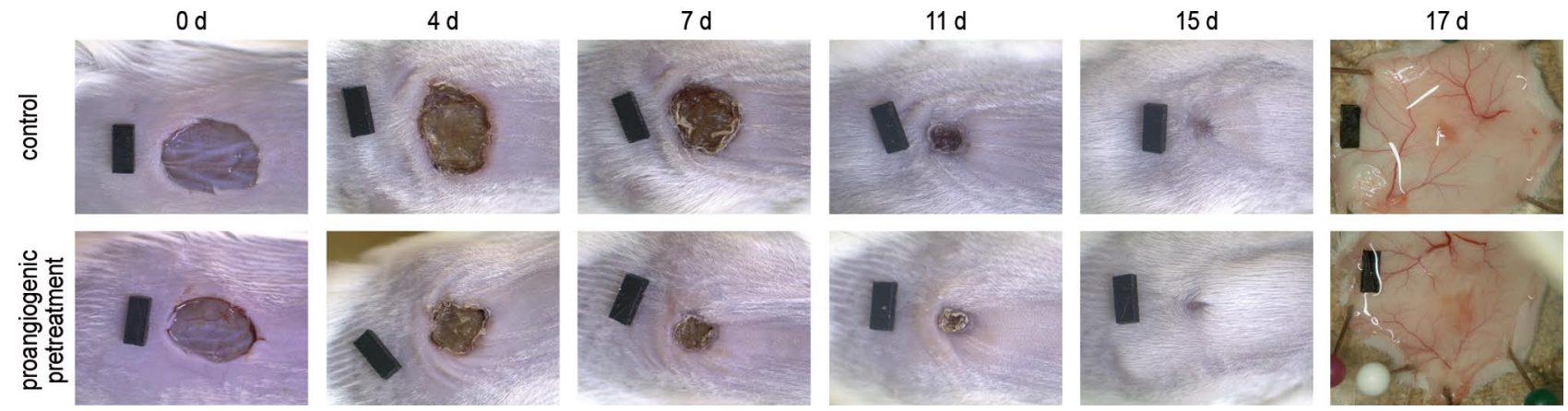

Figure 1. Macroscopic assessment of wound closure as a function of time in representative mice receiving either control treatment (20 $\mu 1$ isotonic saline solution; upper panel) or proangiogenic treatment (a combination of 35.0 $\mu \mathrm{g}$ VEGF, $2.5 \mu \mathrm{g}$ bFGF and $3.5 \mu \mathrm{g}$ PDGF; lower panel) on days 3, 5 and 7 prior to surgery. Note the higher degree of wound contraction in proangiogenic primed group. Day 17 shows the backside of the biopsy specimen. The black marker has a length of $5 \mathrm{~mm}$.

control. Time, force, and displacement were recorded for stretching up until failure. A position encoder (WA300) was used to register the stretching distance; a force transducer (S2, maximum value 150 Newton) was used to quantify the power applied to the tissue strip. The endpoint was the breaking strength in Newton $\left[(\mathrm{kg} \mathrm{x} \mathrm{m}) / \mathrm{s}^{2}\right]$. The resulting values were recorded by a multiple channel PC measuring device (Spider 8, HBM Hottinger Baldwin Messtechnik, Darmstadt) and plotted as force-deflection curve (software: Catman 4.5, all HBM Hottinger Baldwin Messtechnik). The maximum breaking strength was determined from the stressstrain curve.

Statistical analysis. The statistical analysis was performed from measurements obtained in at least 27 different mice. The unpaired Student's t-test for samples of unequal variances was used to calculate statistical significance. The data were expressed as mean \pm standard deviation. The significance level for the sample distribution was defined as $\mathrm{p}<0.05$.

\section{Results}

Gross appearance and wound closure. Despite identical lesion sizes, the proangiogenic pretreated animals presented with a more pronounced wound contraction (Fig. 1). The priming of the wounds with proangiogenic factors showed a temporal advantage in the wound healing process: $50 \%$ wound closure was reached on day 3.9 in the tests vs. day 5.2 in the controls (Fig. 2A). On day 8 we achieved the remaining wound area of 26.1 in the control group vs. 9.5\% in the proangiogenic pretreated group. All proangiogenic pretreated wounds were completely closed on day 10 , whereas on the same day only $22 \%$ of the control group wounds were completely closed (Fig. 2B). All control wounds were completely closed on day 13. Fur growth and hypertrichosis were also accelerated and more pronounced in the proangiogenic pretreated animals. Macroscopically, a more pronounced vessel density was observed in the proangiogenic pretreated group (Fig. 1).

Infrared thermography. The mean temperatures were significantly higher in the proangiogenic pretreated group than in the controls (Fig. 3). The wound margins of the proangiogenic primed animals revealed the highest temperature levels. Here,

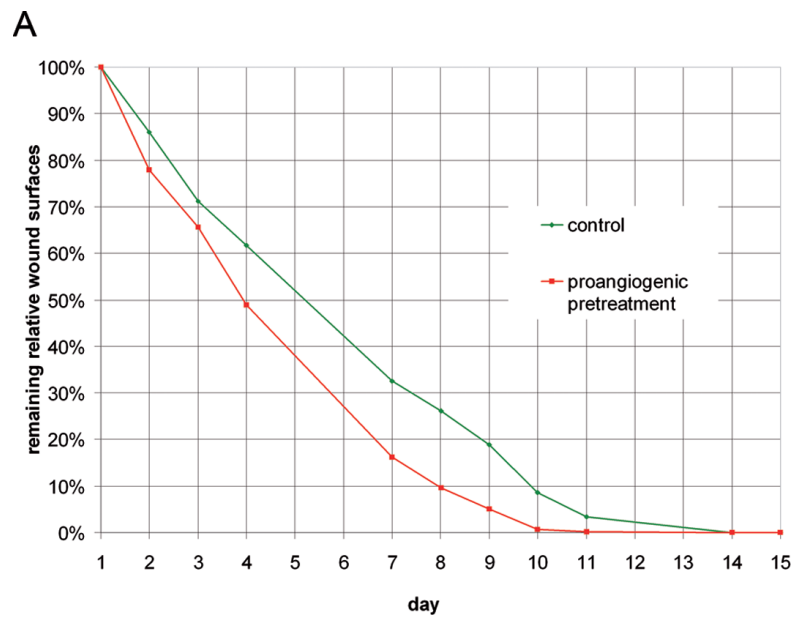

B

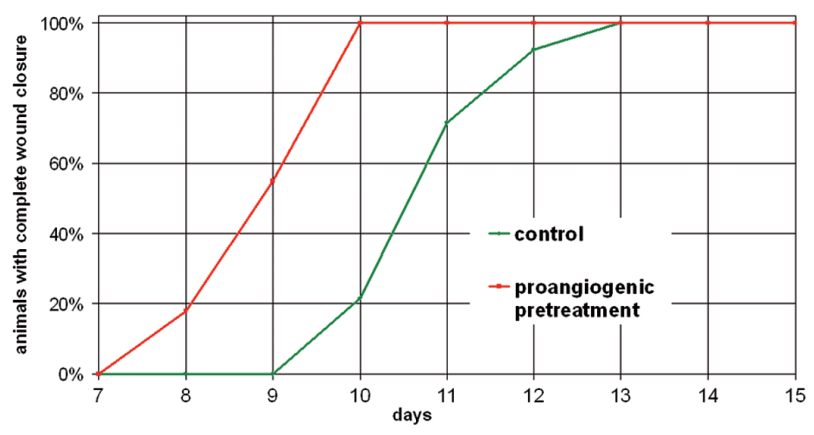

Figure 2. Assessment of wound healing as a function of time after wound induction in mice receiving either control treatment $(20 \mu 1$ isotonic saline solution; green line) or proangiogenic treatment (a combination of $35.0 \mu \mathrm{g}$ VEGF, $2.5 \mu \mathrm{g}$ bFGF and $3.5 \mu \mathrm{g}$ PDGF; red line) on days 3, 5 and 7 prior to surgery; (A) remaining relative wound surface (B) percentage of animals with complete wound closure $(\geq 95 \%)$.

the mean temperature was $0.59^{\circ} \mathrm{C}$ higher compared to the control group, whereas the proangiogenic pretreated wound ground was $0.47^{\circ} \mathrm{C}$ warmer than the one of the controls. In the adjacent vicinity of the wound margin the temperatures of the tests were $0.68^{\circ} \mathrm{C}$ higher.

Vessel density. The vessel densities were determined both in the wounds after sacrificing the animals as well as in the punched skin of the pretreated wound bed on the day of the surgery. 
A

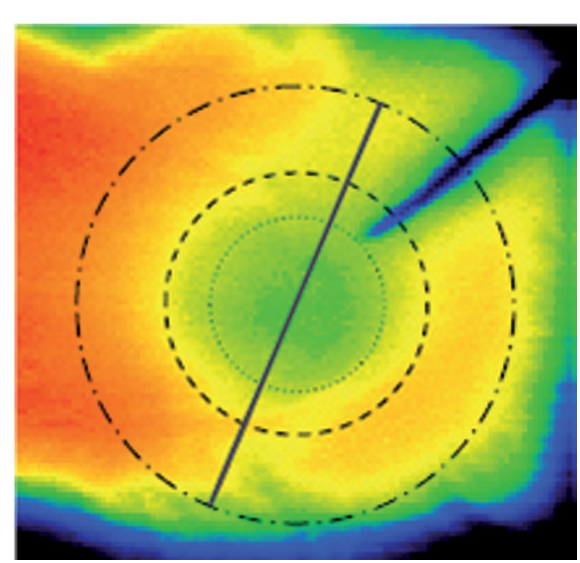

B

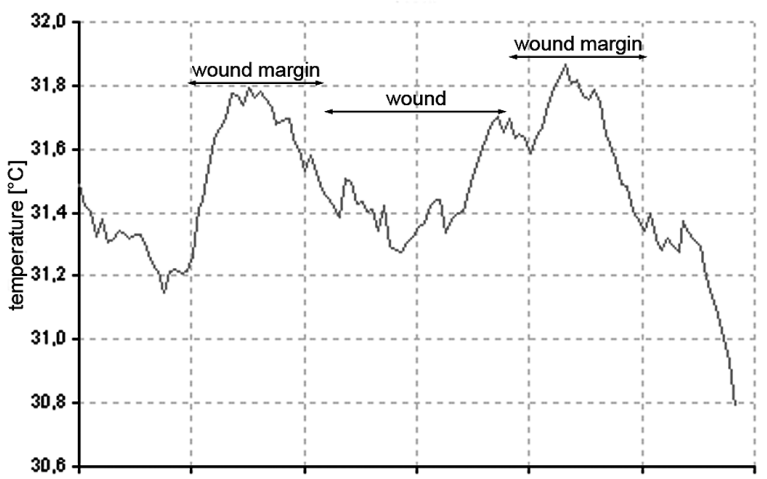

C

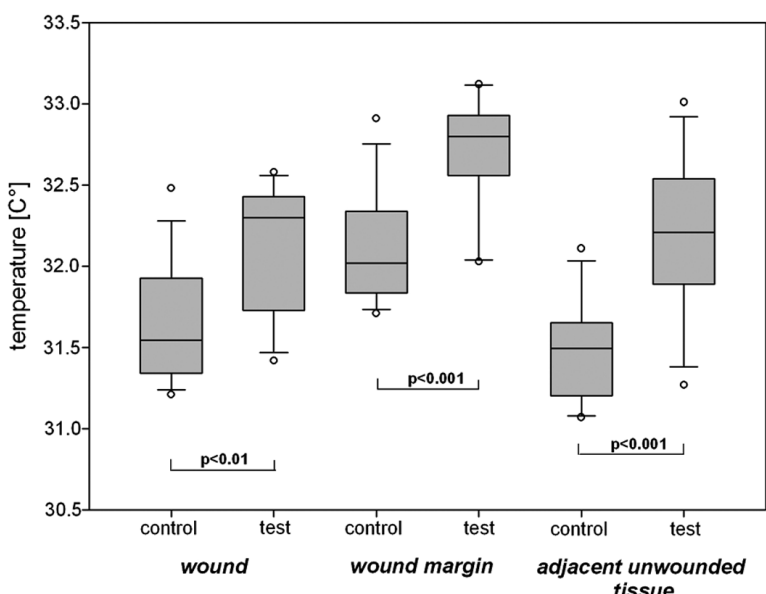

Figure 3. High resolution infrared thermography of full thickness biopsy wounds. (A) A typical example of a line-scan (grey line) thermogram of the wound area (dotted circle), wound margin (dashed circle) and unwounded tissue (dashed dotted circle). (B) The characteristic temperature profile with two prominent humps at the wound margin and decreased temperatures in the wound bed. (C) Temperature levels both in the wound bed, wound margin and adjacent areas are significantly higher in the pretreated test group. Box-whisker plots showing the median, 5th, 10th, 25th, 75th, 90th and 95 th percentiles

Fig. 4A shows that pretreatment resulted in significantly higher percentual vessel densities at the time of the surgery: priming yields more than 4-fold higher vessel surface areas in pretreated group vs. controls (mean: 10.3 vs. $2.4 \%$ vascular surface area).
A

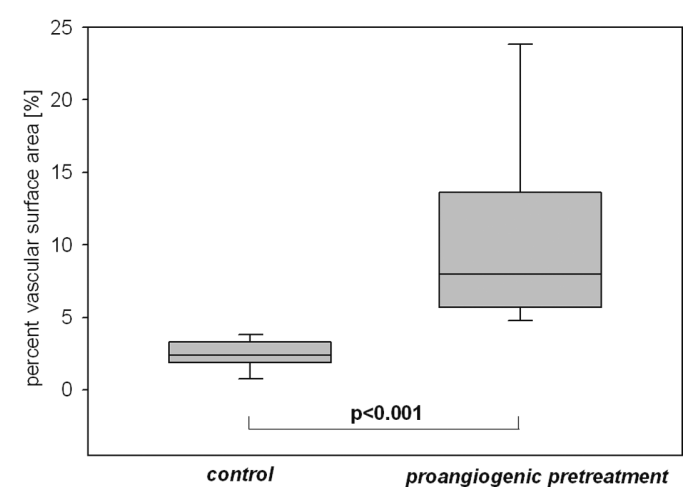

B

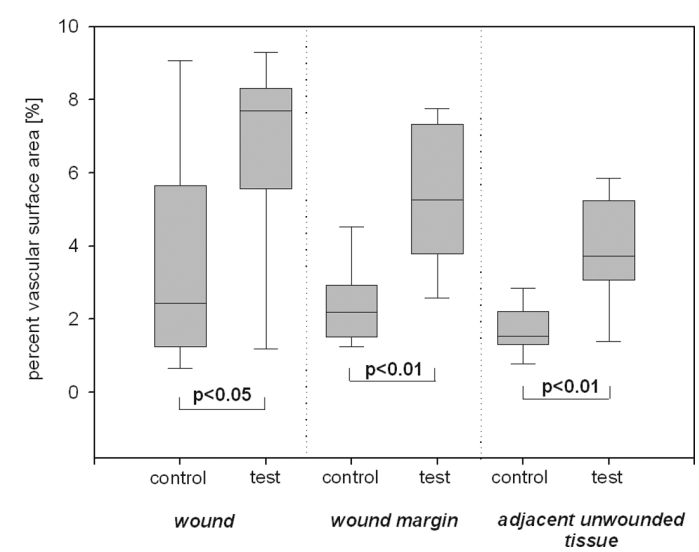

Figure 4. Microvessel density of harvested wound tissue in mice receiving either control treatment ( $20 \mu 1$ isotonic saline solution) or proangiogenic pretreatment (a combination of $35.0 \mu \mathrm{g} \mathrm{VEGF,} 2.5 \mu \mathrm{g}$ bFGF and $3.5 \mu \mathrm{g}$ PDGF) on days 3, 5 and 7 prior to surgery. (A) day 0 (punched tissue). (B) day 17 after wound.

After complete wound closure and harvesting the vessel densities were assessed separately in the wound ground, the former wound margin and in the adjacent unwounded tissue. Fig. 4B illustrates that the values were significantly higher in all measured areas in the proangiogenic pretreated group. Fig. 5 gives some typical examples.

Maximum tensile strength. Functional tensile strength testing revealed a significant advantage of the proangiogenic factor pretreatment in comparison to the sham treated control group: we attained nearly 2 -fold higher breaking strength in the proangiogenic pretreated group ( $\mathrm{p}<0.01$, Fig. 6$)$.

Collagen contents. Significant increases of the percentage of juvenile type III collagen-like fibers after surgery were demonstrated (Fig. 7). Postoperatively, the proangiogenic factor-treated test group showed significantly higher values than the controls $(\mathrm{p}<0.001)$. The levels of type I collagen-like fibers did not change to the same degree (data not shown).

\section{Discussion}

The present study, to our knowledge, is the first to investigate the effects of subcutaneous priming with proangiogenic factors on wound healing. It shows that priming with a combination of 

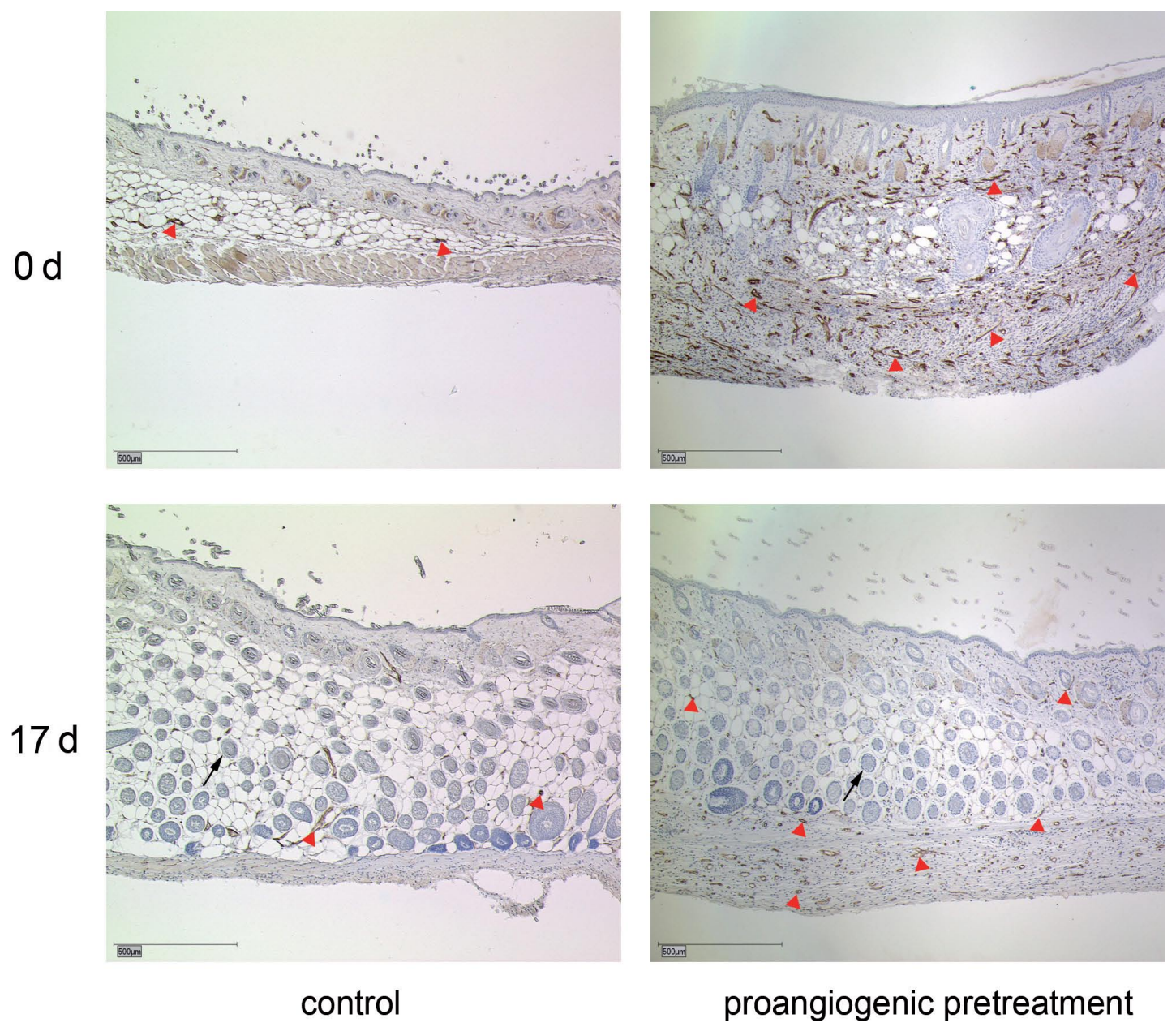

Figure 5. Vascularization of excised skin punch biopsies in control- and pretreated animals on the day of surgery ( 0 day) and of the wound tissue one week after complete closure (17 day). Note the higher vessel density (red arrowheads highlight vessels) in the pretreated group on the day of surgery and on day 17 as well as the hypertrichosis in the newly formed, healed tissue. Arrows point exemplary to hair follicles. Anti-CD31 staining. Bars, $500 \mu \mathrm{m}$.

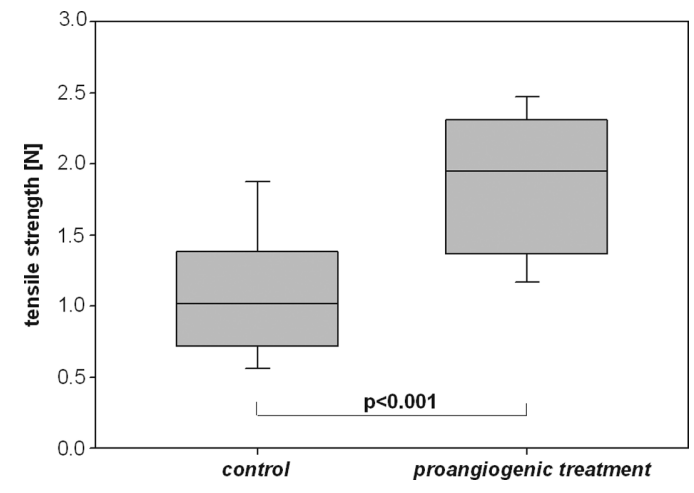

Figure 6. Comparison of tensile strength values obtained on day 17 after surgery. Mice received either control treatment $(20 \mu 1$ isotonic saline solution) or proangiogenic treatment (a combination of $35.0 \mu \mathrm{g}$ VEGF, $2.5 \mu \mathrm{g}$ bFGF and $3.5 \mu \mathrm{g}$ PDGF) on days 3,5 and 7 prior to surgery. Box whisker plots showing the median, 10th, 25th, 75th, 90th percentiles.

proangiogenic factors (VEGF, bFGF, and PDGF) can significantly accelerate wound healing. In particular, assessment of time-to-closure and functional outcome revealed a significant advantage for the proangiogenic pretreated group in comparison to the control animals. In addition, we observed a higher

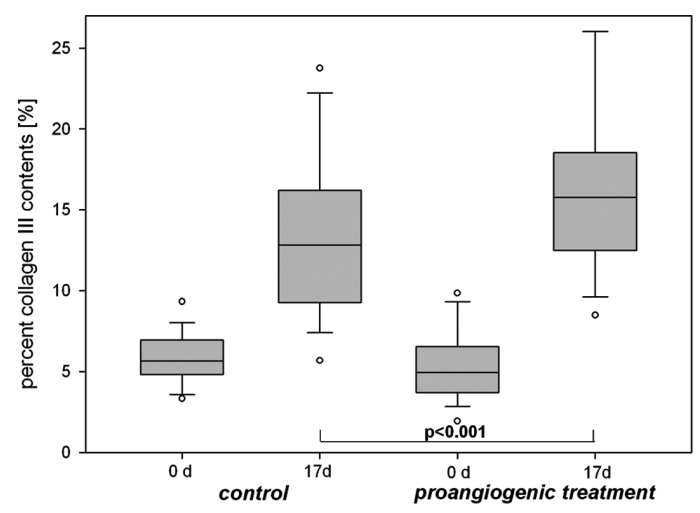

Figure 7. Assessment of juvenile type III collagen-like fibers at day 17 after wounding using picrosirius red staining. Mice received either control treatment $(20 \mu 1$ isotonic saline solution) or proangiogenic treatment (a combination of $35.0 \mu \mathrm{g}$ VEGF, $2.5 \mu \mathrm{g}$ bFGF and $3.5 \mu \mathrm{g}$ PDGF) on days 3 , 5 and 7 prior to surgery. Contents of juvenile type III collagen-like fibers in the resected tissue (day 0) and in the harvested wound (day 17) showing significantly higher values in the pretreated test group. Box-whisker plot showing the median, 5 th, $10 \mathrm{th}, 25 \mathrm{th}, 75 \mathrm{th}, 90 \mathrm{th}$, and 95 th percentiles.

degree of wound contraction immediately after wounding in the proangiogenic factors pretreated group. Healing by contraction is more predominant than epithelialization in 
loose skin animals and depends on vascularization, which is elevated in proangiogenic primed group and which correlates with myofibroblast activity (26).

This study was designed as a pilot study focusing primarily on the functional outcome and the time to closure as a primary endpoint. Histological assessments were carried out only on day 0 and 7 after complete closure. Infrared thermography was used instead for monitoring the healing process non-invasively.

Factors contributing to the quality of wound healing include not only the time required for the wound to close, but also the functional properties of the new skin, an aspect which is receiving increased attention. Additionally, from the findings presented here, it would appear that angiogenesis is strongly related to the tensile strength of the newly formed epidermis and dermis, as revealed by significantly higher breaking strength values.

Collagen is the major component of ECM and provides tensile strength to the skin. Gabbiani et al (27) found that granulation tissue in rat wounds contained proportionally more type III collagen. In our study, the collagen deposition was altered towards a higher level of juvenile type III collagenlike fibers following the application of the proangiogenic growth factors, suggesting intensified tissue remodeling by vascularized tissue similarly to the granulation tissue. A stringent link between collagen content and functional outcome, in particular breaking strength, should, however, not be presumed. Our recent observations on the abdominal wall nevertheless confirm the notion that cross-linking and interfacing of collagen bundles can be seen as a pivotal criterion influencing breaking strength (unpublished data). In the literature, there are opposing observations on the effects of PDGF on tensile strength. Ashraf et al (28) have demonstrated that a sustained release of PDGF leads to a paradoxical decrease of wound breaking strength in an impaired wound healing model, whereas Eming et al (29) have shown a significant increase of tensile strength by PDGF-gene transfer. Our priming experiments support the thesis of beneficial effects of PDGF on breaking strength. In further experiments we will focus on priming with single proangiogenic growth factors, such as PDGF and VEGF, and their influence on tensile strength in normal and impaired diabetic wound healing.

The application of VEGF has been reported to increase vascular permeability, with a maximum effect being seen 2-3 days after wound placement, primarily in postcapillary venules and small veins. Brown et al (30) described leaky vessels which were initially seen at the wound margin, and later on became most prominent in the subepidermal granulation tissue. At that time microvessel density reaches its maximum increase during the wound healing process (31). An increased permeability of microvessels is also an important facet necessary for the interaction with the surrounding ECM and for tissue remodeling (32). If new blood vessels and supporting connective tissue are to develop in wound tissue, e.g., as a response to the increased metabolic needs in the wound healing process, native tissue stroma must be replaced with a new matrix structure that supports migration of endothelial cells and fibroblasts (30). In this context, priming with angiogenic factors could allow a preconditioning of the wound bed. For example, application of VEGF on the one hand leads to a hyperpermeability of microvessels which facilitates the early steps of wound healing (extravasation, infiltration, granulation tissue) and on the other to the induction of angiogenesis prior to surgery so that when a wound is inflicted, a newly formed vessel network is already 'waiting' to cope with the inflicted insult to the tissue.

Pretreatment with proangiogenic factors in the present study led to higher tissue temperatures, measured by infrared thermography, and can be assumed to indicate a higher level of vascularization and local tissue perfusion. In addition, infrared thermography appears to be a reliable surrogate parameter for the assessment of local tissue perfusion in wounds (33). A correlation between levels of vessel densities and higher temperature warrants further discussion, especially since a high vessel density alone does not necessarily result in an increase in local tissue perfusion. In particular, the influence of vasoregulation on blood flow in remodeled tissue appears to be a crucial element in the control of perfusion $(34,35)$. Normal blood vessels respond to specific physiological signals from the tissue they are supporting and from the perivascular microenvironment (36). Nevertheless, the stimulation of vascularization through application of angiogenic factors is thought to be capable of significantly increasing local tissue perfusion (36).

Wound healing is a well-regulated continuum of vessel induction and regression $(31,37)$. In healing wounds, rising levels of proangiogenic growth factors induce a period of robust angiogenesis. After that, a period of vessel regression is seen during which capillarity density returns to a level comparable to that found in normal skin (18). Immature blood vessels have been reported to regress as a consequence of withdrawing VEGF. Exogenous proangiogenic factors applied by priming in addition to endogenous growth factors released in the wound healing process may improve stabilization of vessel networks by VEGF as a 'vessel survival factor' (30) and may effect a certain latent period of vessel regression.

Reports $(37,38)$ reviewing the therapeutic influence of proangiogenic growth factors on the success of wound healing have found a wide spectrum of results. In general, the dosage and mode of application seem to represent the variables with the highest impact in terms of boosting angiogenesis in wound healing. Where topically applied growth factors have been seen to be ineffective (20) this lack of effect may be due to a proteloytic degradation of factors at the wound site.

To conclude, in addition to a gene therapeutic concept (37) priming could represent a potential therapeutic approach for improving the vascularization of the skin prior to elective surgery, especially in patients in which a compromised wound healing might be expected. Following the therapeutic success of priming with proangiogenic factors in normoglycemic mice in the present pilot study, further research will focus on the effects of priming in a diabetic mouse model, in which an assessment of morphological and functional outcome in diabetes-related impaired healing will be possible. Furthermore, an optimization of the growth factor combination and the ideal time points is warranted.

\section{Acknowledgements}

This study was supported by grants of the German Army to M.A.K. and A.W. (M-SAB 1-5-A009) and by the Angiogenesis 
Foundation. The authors acknowledge skillful technical assistance of Ms. Kerstin Bahr and thank Dr Bickes-Kelleher and Dr George Broughton for critical review of the manuscript.

\section{References}

1. Li WW, Talcott KE, Zhai AW, Kruger EA and Li VW: The role of therapeutic angiogenesis in tissue repair and regeneration. Adv Skin Wound Care 18: 491-500, 2005.

2. Risau W: Mechanisms of angiogenesis. Nature 386: 671-674, 1997.

3. Dvorak HF: Tumors: wounds that do not heal. Similarities between tumor stroma generation and wound healing. N Engl J Med 315: 1650-1659, 1986.

4. Carmeliet P: Angiogenesis in health and disease. Nat Med 9: 653-660, 2003

5. Harding KG, Morris HL and Patel GK: Science, medicine and the future: healing chronic wounds. BMJ 324: 160-163, 2002.

6. Brem H and Tomic-Canic M: Cellular and molecular basis of wound healing in diabetes. J Clin Invest 117: 1219-1259, 2007.

7. Schramm JC, Dinh T and Veves A: Microvascular changes in the diabetic foot. Int J Low Extrem Wounds 5: 149-159, 2006.

8. Falanga V: Wound healing and its impairment in the diabetic foot. Lancet 366: 1736-1743, 2005.

9. Bauer SM, Bauer RJ and Velazquez OC: Angiogenesis, vasculogenesis, and induction of healing in chronic wounds. Vasc Endovascular Surg 39: 293-306, 2005.

10. Singer AJ and Clark RA: Cutaneous wound healing. N Engl J Med 341: 738-746, 1999.

11. Broughton G II, Janis JE and Attinger CE: The basic science of wound healing. Plast Reconstr Surg 117 (Suppl 7): S12-S34, 2006.

12. Barrientos S, Stojadinovic O, Golinko MS, Brem H and Tomic-Canic M: Growth factors and cytokines in wound healing. Wound Repair Regen 16: 585-601, 2008.

13. Heldin $\mathrm{CH}$ and Westermark B: Mechanism of action and in vivo role of platelet-derived growth factor. Physiol Rev 79: 1283-1316, 1999.

14. Holzbach T, Neshkova I, Vlaskou D, Konerding MA, Gansbacher B, Biemer E and Giunta RE: Searching for the right timing of surgical delay: angiogenesis, vascular endothelial growth factor and perfusion changes in a skin-flap model. J Plast Reconstr Aesthet Surg 62: 1534-1542, 2009.

15. Pierce GF, Mustoe TA, Altrock BW, Deuel TF and Thomason A Role of platelet-derived growth factor in wound healing. J Cell Biochem 45: 319-326, 1991.

16. Corral CJ, Siddiqui A, Wu L, Farrell CL, Lyons D and Mustoe TA Vascular endothelial growth factor is more important than basic fibroblastic growth factor during ischemic wound healing. Arch Surg 134: 200-205, 1999.

17. Saaristo A, Tammela T, Farkkila A, Kärkkäinen M, Suominen E, Yla-Herttuala S and Alitalo K: Vascular endothelial growth factor- $C$ accelerates diabetic wound healing. Am J Pathol 169: 1080-1087, 2006.

18. Gosain A, Matthies A, Dovi JV, Barbul A, Gamelli RL and DiPietro LA: Exogenous pro-angiogenic stimuli cannot prevent physiologic vessel regression. J Surg Res 135: 218-225, 2006.

19. Martin P: Wound healing - aiming for perfect skin regeneration. Science 276: 75-81, 1997.

20. Smiell JM, Wieman TJ, Steed DL, Perry BH, Sampson AR and Schwab BH: Efficacy and safety of becaplermin (recombinant human platelet-derived growth factor-BB) in patients with nonhealing, lower extremity diabetic ulcers: a combined analysis of four randomized studies. Wound Repair Regen 7: 335-346, 1999.
21. Chan RK, Liu PH, Pietramaggiori G, Ibrahim SI, Hechtman HB and Orgill DP: Effect of recombinant platelet-derived growth factor (Regranex) on wound closure in genetically diabetic mice. J Burn Care Res 27: 202-205, 2006.

22. FDA Wound Healing Clinical Focus Group: Guidance for industry: chronic cutaneous ulcer and burn wounds - developing products for treatment. Wound Repair Regen 9: 258-268, 2001.

23. McGuiness W, Vella E and Harrison D: Influence of dressing changes on wound temperature. J Wound Care 13: 383-385, 2004.

24. Cuttle L, Nataatmadja M, Fraser JF, Kempf M, Kimble RM and Hayes MT: Collagen in the scarless fetal skin wound: detection with picrosirius-polarization. Wound Repair Regen 13: 198-204, 2005.

25. Weibel ER, Kistler GS and Scherle WF: Practical stereological methods for morphometric cytology. J Cell Biol 30: 23-38, 1966.

26. Alizadeh N, Pepper MS, Modarressi A, Alfo K, Schlaudraff K, Montandon D, Gabbiani G, Bochaton-Piallat ML and Pittet B: Persistent ischemia impairs myofibroblast development in wound granulation tissue: a new model of delayed wound healing. Wound Repair Regen 15: 809-816, 2007.

27. Gabbiani G, Le Lous M, Bailey AJ, Bazin S and Delaunay A: Collagen and myofibroblasts of granulation tissue. A chemical, ultrastructural and immunologic study. Virchows Arch B Cell Pathol 21: 133-145, 1976.

28. Ashraf A, Lee PH, Kim K, Zaporojan V, Bonassar L, Valentini R, Spangenberger A and Weinzweig J: Effect of sustained-release PDGF and TGF-beta on cyclophosphamide-induced impaired wound healing. Plast Reconstr Surg 124: 1118-1124, 2009.

29. Eming SA, Whitsitt JS, He L, Krieg T, Morgan JR and Davidson JM: Particle-mediated gene transfer of PDGF isoforms promotes wound repair. J Invest Dermatol 112: 297-302, 1999.

30. Brown LF, Yeo KT, Berse B, Yeo TK, Senger DR, Dvorak HF and van de Water L: Expression of vascular permeability factor (vascular endothelial growth factor) by epidermal keratinocytes during wound healing. J Exp Med 176: 1375-1379, 1992.

31. Brown NJ, Smyth EA, Cross SS and Reed MW: Angiogenesis induction and regression in human surgical wounds. Wound Repair Regen 10: 245-251, 2002.

32. Nguyen LL and D'Amore PA: Cellular interactions in vascular growth and differentiation. Int Rev Cytol 204: 1-48, 2001.

33. Merla A, Di Romualdo S, Di Donato L, Proietti M, Salsano F and Romani GL: Combined thermal and laser Doppler imaging in the assessment of cutaneous tissue perfusion. Conf Proc IEEE Eng Med Biol Soc 2007: 2630-2633, 2007.

34. He CF, Cherry GW and Arnold F: Postural vasoregulation and mediators of reperfusion injury in venous ulceration. J Vasc Surg 25: 647-653, 1997.

35. Jain RK, Au P, Tam J, Duda DG and Fukumura D: Engineering vascularized tissue. Nat Biotechnol 23: 821-823, 2005

36. Pries AR and Secomb TW: Origins of heterogeneity in tissue perfusion and metabolism. Cardiovasc Res 81: 328-335, 2009.

37. Holzbach T, Vlaskou D, Neshkova I, Konerding MA, Wörtler K, Mykhaylyk O, Gänsbacher B, Machens HG, Plank C and Giunta RE: Non-viral VEGF gene therapy - Magnetofection of acoustically active magnetic lipospheres ('Magnetobubbles') increases tissue-survival in an oversized skin flap model. J Cell Mol Med 14: 587-599, 2010.

38. Galiano RD, Tepper OM, Pelo CR, Bhatt KA, Callaghan M, Bastidas N, Bunting S, Steinmetz HG and Gurtner GC: Topical vascular endothelial growth factor accelerates diabetic wound healing through increased angiogenesis and by mobilizing and recruiting bone marrow-derived cells. Am J Pathol 164: 19351947,2004 